\title{
Comercio informal transfronterizo México-Guatemala desde una perspectiva de frontera permisiva
}

\section{Informal transborder trade between México and Guatemala from a permissive border perspective}

\author{
Carlos Ernesto Ruiz Juárez* y Germán Martínez Velasco**
}

Resumen

En este documento se abordan procesos de interacción, tensión, conflicto e intereses en la zona fronteriza entre México y Guatemala. En el comercio informal transfronterizo participan actores con cuya agencia despliegan transacciones sociales, políticas, económicas y territoriales, más allá del límite fronterizo. Con base en una perspectiva conceptual sustentada en la relación dialéctica entre la frontera límite como tal y el accionar de los actores fronterizos, se concluye que en la zona de estudio se ha conformado un proceso de integración comercial transfronterizo de corte informal, que en los hechos trasciende la frontera límite para dar paso a una frontera permisiva.

Palabras clave: frontera México-Guatemala, interacciones, comercio transfronterizo, territorialidad, agencia, informalidad.

\begin{abstract}
This paper analyzes processes of interaction, tension, conflict and economic interests in one of the major border areas between Mexico and Guatemala. Informal transborder trade involves several actors who have been building these processes pursuant to agency initiatives. From a conceptual perspective, supported by the dialectical relationship between the notions of a border the behavior of transborder actors, it is concluded that in the study area, an informal border-trade integration process has developed and its actors transcend the border, rendering that border permissive.

Keywords: México-Guatemala border, interactions, tensions and border conflicts, agency, informality.
\end{abstract}

Recibido: 22 de agosto de 2013.

Aprobado: 24 de octubre de 2014.

* El Colegio de la Frontera Sur, egresado de la Maestría en Ciencias en Recursos Naturales y Desarrollo Rural. Profesor de Sociología en la escuela preparatoria Jaime Sabines Gutiérrez de Cacahoatán, Chiapas. Dirección: Carretera Panamericana y Periférico Sur s/n, Barrio María Auxiliadora, San Cristóbal de las Casas, Chiapas, C.P. 29290. Correo electrónico: ceruiz@ecosur.edu.mx

** El Colegio de la Frontera Sur, Chiapas, México. Correo electrónico: gmartínez@ ecosur.edu.mx 
Carlos Ernesto Ruiz Juárez y Germán Martínez Velasco / Comercio informal transfronterizo México-Guatemala

\section{Introducción}

Si bien desde los sucesos acaecidos en la década de los ochenta con motivo de la oleada de refugiados guatemaltecos a México, la frontera sur había representado solamente un espacio de administración de flujos de personas, bienes y servicios por parte del Estado mexicano, con los atentados del 11 de septiembre de 2001 en Estados Unidos y el clima de narcoviolencia vivido en México a partir del 2005, se transformó en objeto de atención internacional (Martínez, 2014). Sucesos constituidos en incentivos para que las elites nacionales firmaran el programa de seguridad denominado Iniciativa Mérida, ${ }^{1}$ aprobado por el Senado estadunidense en junio de 2008 argumentando las posibilidades de que en las fronteras pudieran transitar personas indeseables, armamento y drogas, poniendo en riesgo la seguridad nacional de los Estados Unidos de América.

Por otra parte, en relación con los acuerdos comerciales de México signados con sus vecinos del sur con el fin de establecer medidas de seguridad recíprocas, en la xin Cumbre de Tuxtla, llevada a cabo el 5 de diciembre de 2011, los presidentes en turno de México, Guatemala, Honduras, El Salvador, Nicaragua y Costa Rica sellaron la declaratoria del Tratado de Libre Comercio entre el primer país y Centroamérica en su conjunto. Sin embargo, según Rodríguez (2008), debe tomarse en cuenta que los acuerdos de índole comercial entre países responden más a consideraciones geopolíticas anidadas en el tema de la seguridad nacional que a un verdadero intercambio económico entre países de la región. Cabe señalar que los Tratados de Libre Comercio (TLC) que México ha firmado con Centroamérica son: a) el acuerdo México-Costa Rica, vigente desde el primero de enero de 1995; b) el de México-Nicaragua, vigente desde el primero de julio de 1998; y c) el de México-El Salvador, Guatemala y Honduras, vigente desde el 15 de marzo de 2001 (Sistema de Información sobre Comercio Exterior [SICE], 2014). No obstante, con la emergencia de la firma del Tratado de Libre Comercio de América del Norte (TLCAN), desde 1994 hubo de

facto discontinuidad comercial entre México y Centroamérica; reduciendo

${ }^{1}$ A la Iniciativa Mérida anteceden otras de gran importancia para la seguridad fronteriza, entre las que destacan el "Plan Sur" y la formación del Grupo de Alto Nivel para la Seguridad Fronteriza (GANSEF) entre los gobiernos de Guatemala y México (Villafuerte, 2008, p. 198). 
sus fronteras en términos de posicionamientos geo-estratégicos más que comerciales (Ordoñez, 2005).

En efecto, más allá de los ámbitos de la seguridad fronteriza o de acuerdos de tipo comercial, y al margen de las políticas de los Estados nacionales involucrados, los actores locales mantienen vigentes aquellos procesos de larga data, configurando una red de interacciones transfronterizas como los de la inmigración laboral o, como el caso que ocupa esta contribución, del intercambio comercial informal entre espacios adyacentes separados por la frontera límite. Así, la pregunta a responder en el presente documento consiste en: ¿Cuáles son los procesos de interacción, tensión, conflicto e intereses económicos que surgen a partir del comercio transfronterizo informal en la frontera Tecún Umán-Ciudad Hidalgo? Consecuentemente, el objetivo consiste en exponer las interacciones que llevan a cabo los actores involucrados en el fenómeno citado, cuyos ejercicios de agencia permiten trascender la noción de frontera límite para alcanzar la de frontera permisiva.

Este artículo se deriva de una investigación realizada en 2012 en el área transfronteriza y conurbada de Ciudad Hidalgo-Tecún Umán. Con base en identificación de figuras sociales claves que intervienen en el objeto de estudio, se procedió a indagar aspectos subjetivos de los actores locales, llevando a cabo pláticas informales, entrevistas abiertas y observaciones de campo en relación con valores, reflexiones, opiniones y comportamientos sobre el comercio y tránsito de mercancías, así como del medio de transporte de un país a otro. Mediante una cédula tipo cuestionario, se procedió a generar una serie de indicadores socioeconómicos como ingresos económicos por actividad laboral y volúmenes de mercadería que fluyen de México a Guatemala. Esta contribución presenta entonces tanto información proveniente del análisis cualitativo que nos da cuenta de los procesos de interacción, tensión y conflictos asociados al fenómeno en cuestión, como del cuantitativo en relación con aspectos económicos-laborales de los principales actores, como el de los camareros, la derrama económica de los comerciantes transfronterizos guatemaltecos de lado mexicano y el ingreso monetario por concepto de ventas de minoristas y mayoristas mexicanos.

El artículo se divide en cuatro apartados. En el primero se plantean las nociones conceptuales que sirven como punto de abordaje de la temática 
enunciada; el segundo aborda los procesos de interacción, tensión y conflictos de los actores involucrados en el comercio informal transfronterizo. En el tercero se describen las expresiones económicas de las transacciones presentando indicadores que dimensionan el comercio transfronterizo informal. En el cuarto y último apartado, con base en la articulación de conceptos inicialmente expuestos, más otros ahí planteados, a manera de punto de llegada, se plantea un ensayo de interpretación teórica de resultados, posicionando a la vez la noción de frontera permisiva.

\section{El punto de partida conceptual}

En el ámbito de la frontera norte de México hubo consenso de que una de las determinantes de lo transfronterizo es la contigüidad geográfica de regiones de diferencias estructurales (Alegría, 1989 y 1990), reflejadas éstas en la disparidad de precios y salarios. Siendo regiones pertenecientes a distintos territorios nacionales, sus diferencias habrían de facilitar procesos de interacción, los que a su vez se entienden como "las conductas de los individuos mutuamente orientadas con el objetivo de satisfacer distintas necesidades" (Bustamante, 1989, p. 11). Esto lleva implícito el cruce de la frontera y sus ámbitos de expresión en términos culturales, económicos y sociales (Odgers, 2006; Ruiz, 1992; Iglesias-Prieto, 2010). De ahí que lo transfronterizo supere a las transacciones económicas para abarcar otras prácticas cotidianas permeadas de conocimientos y vivencias trascendiendo en uno u otro sentido la circunscripción fronteriza (Odgers, 2006; Ruiz, 1992). En esa interacción, habría de generarse una identidad propia de frontera haciendo distintos los actores fronterizos de sus respectivos connacionales (Ojeda, 2009). De ese modo, la frontera se convierte en un recurso no sólo económico, sino también sociocultural, "[debido] precisamente a las diferencias que existen a un lado y otro de la línea [...] a los contrastes a los que la frontera da un soporte" (Odgers, 2006, p. 122).

En ese tenor, surge una relación dialéctica entre las subjetividades de los individuos y la frontera física que se redefine día a día dependiendo del grado de interacción, de la escala de los intercambios subjetivos y materia-

les, de la frecuencia y direccionalidad de los cruces, es decir, del grado de transfronteridad (Iglesias-Prieto, 2010). 
Por su parte, Grimson establece que lo transfronterizo no sólo está determinado por la fusión de culturas o el intercambio simbólico y material, sino también por "las distinciones y conflictos, las luchas de poder, los estigmas persistentes y las nuevas formas de nacionalismo" (Grimson, 2000a, p. 1; 2001, p. 90). Con base en métodos etnográficos, este autor recupera la noción de agencia de los actores locales, entendiendo dicho concepto como la capacidad de incidir en los cambios del entorno natural y social. Con ello se evita generalizar que la influencia sólo ocurre de arriba hacia abajo o del centro hacia la periferia, contrariamente a la relación dialéctica entre los gobiernos y los actores fronterizos. De ese modo, lo transfronterizo se redefine día a día partiendo de procesos de interacción, tensión y conflicto entre los distintos actores, siendo así como éstos "hacen la frontera" (Andrade, 2010, p. 180).

El papel del Estado se mantiene omnipresente en el tratamiento de las fronteras en un doble sentido: “ $a$ ) frontera internacional, límite entre estados (border); $b$ ) espacio flexible de articulación entre sistemas con dinámicas socioeconómicas heterogéneas donde uno se expande sobre el otro (frontier)" (Grimson, 2001); al tiempo que flexibiliza sus fronteras en relación con los flujos de capital y bienes producidos por las elites (frontera frente), las restringe para las interacciones ocurridas desde abajo, las de los actores fronterizos locales (frontera límite) (Grimson, 2001).

Entre el actuar de los Estados nacionales y el de los actores fronterizos, las fronteras adquieren nuevas connotaciones, usos y significados; atributos conferidos en el estudio de Dorfman y Cardin (2014) en el que se señala que en los límites del Cono Sur coexisten los territorios estatales y privados donde la sociedad civil construye redes que activan una frontera.

Otras contribuciones provenientes del Sur están referidas a los interesantes ensayos de Renoldi, Benedetti y Salizzi, así como el de Albuquerque cuyas contribuciones abordan las variaciones encontradas entre los países que conforman esa vasta región. Renoldi (2013), en su análisis de la frontera de Argentina, Paraguay y Brasil, llega a la conclusión de que la frontera para los actores fronterizos se presenta al mismo tiempo como un recurso y una limitación. La idea de limitación cobra sentido en tanto las fronteras son una realidad; aun cuando éstas sean construcciones sociales, "cada uno vive las fronteras como una experiencia de relaciones capaz 
de ir mucho más allá de los controles aduaneros o migratorios que pasan a ser apenas un aspecto de todo lo que habita estos espacios" (Renoldi, 2012, p. 137). Por su parte, Benedetti y Salizzi (2011), estudiando distintas conurbaciones de la frontera Argentina-Bolivia, identifican una superposición de territorialidades, unas fijas, las otras móviles; algunas marcadas por relaciones de horizontalidad y otras de verticalidad, son rutinarias o permanentes, antiguas, modernas y posmodernas, de interés puramente simbólico o instrumentales, cuyas interacciones pueden alcanzar poca o mucha extensión geográfica. Finalmente, Albuquerque (2010) compila y analiza los trabajos de corte histórico para las fronteras del Brasil en su momento hechos por Sergio Buarque de Holanda. Para fines del presente trabajo, sólo es posible subrayar los usos distintos que el historiador hizo de los conceptos de frontera frente y frontera de expansión en relación con lo expuesto por Frederick Jackson Turner en 1893. La distinción estriba en que mientras en la expansión de la frontera norteamericana ésta ocurrió de forma bélica ante los originarios de esas tierras, en el caso del Brasil, sucedió en el marco de un estrecho contacto cultural entre colonizadores y poblaciones aborígenes (Albuquerque, 2010).

En el marco de la frontera México-Guatemala, los esfuerzos intelectuales básicamente descansan en dos estudiosos del tema: Jan de Vos y Andrés Fábregas. El primero historiza los distintos tiempos de expansión de las fronteras en su carácter de frente de expansión, desde la época prehispánica, pasando por el periodo colonial hasta los recientes proyectos económicos acaecidos en el lado mexicano. Señala entonces que la segunda acepción de frontera (frontier) conlleva un mayor valor heurístico para explicar el sometimiento no solamente de los mayas chiapanecos sino también el de los guatemaltecos (De Vos, 2002). Por su parte, Fábregas, igualmente hace un recorrido de la formación de la frontera sur, a partir de tres grandes proyectos de expansión del Estado mexicano: la anexión de Chiapas a México (1824); el establecimiento de fincas de café y monterías a partir del tratado de límites con Guatemala (1882); y el proyecto agrario de Lázaro Cárdenas y la expansión indígena hacia la selva Lacandona (Fábregas, 1996). La todavía usual conceptualización de Turner, retomada por De Vos e inherentemente en Fábregas, propició la aplicación de tal perspectiva en el análisis de los refugiados guatemaltecos a Chiapas en el marco de la guerra de contrainsurgencia del Estado guatemalteco. Así, 
Kauffer (2005) utiliza dichos conceptos para analizar, primero, cómo a partir de la llegada de refugiados guatemaltecos a México durante la década de los años ochenta, el gobierno de este país consideró a la frontera sur como zona prioritaria para la seguridad nacional, lo cual se reflejó en el incremento de sus cuerpos de seguridad en la región (frontera límite), y segundo, la ampliación de la frontera agrícola por parte de los refugiados (frontera frente) como un hecho concomitante a su llegada (Kauffer, 2005). Como puede apreciarse, todavía sigue pendiente una agenda de investigación sobre la mutidimensionalidad que la frontera sur de México ostenta, más aún si se analiza desde su componente transfronterizo y desde marcos interpretativos distintos.

Para abordar la presente temática, tanto los enfoques arriba descritos desde los ámbitos de la frontera norte y sur de México, como los del Cono Sur, lejos de ser contradictorios resultan complementarios de acuerdo al objeto de estudio en cuestión. Por ejemplo, el concepto de frontera límite (Turner, 1987), además de su clásica utilización como la línea que divide a dos territorios nacionales, también es útil al analizar cómo dicho límite se desempeña como soporte para la contigüidad de dos regiones con diferencias en precios y salarios, y con ello validar la noción de colindancia de diferencias estructurales (Alegría, 1989, 1990 y 2007). De esa forma esos espacios constituyen dimensiones económicas y sociales, al tiempo que sirven de cobertura para la actuación de los actores quienes previamente hacen una valoración sobre lo existente del otro lado del límite (Ruiz, 1992) y de lo cual pueden o no hacer uso o, en su caso, apropiarse.

En el despliegue de acciones por parte de los actores locales, se ha de superar la noción de frontera límite para trascender a la noción de frontera permisiva, como los márgenes de tolerancia que los Estados nacionales pueden conceder según las coyunturas políticas y económicas en sus zonas de frontera, producto ya sea de los advenimientos históricos o de los implementados circunstancialmente ante la agencia de los actores fronterizos que pueden convertirse en prácticas cotidianas de plazo indefinido.

Con el concepto de frontera permisiva se abordan las situaciones de frontera que, con el paso del tiempo, transfiguran sus espacios, convirtiendo a ella en territorio dinámico y flexible, de condición porosa en el que el Estado por acción u omisión ha de mostrar determinados grados de anuencia. 
De acuerdo con Bustamante (1989), entendemos el concepto de interacción transfronteriza como las conductas de los individuos orientadas mutuamente hacia otros con el objetivo de satisfacer distintas necesidades, [en el que] dichos individuos fluyen en movimientos de ida y vuelta a través de la frontera. Del mismo modo, con base en la obra de Ruiz (1992), definimos la valoración de conocimientos por parte de los actores de frontera como el análisis que ellos hacen acerca del costo-beneficio que implica el cruce de la frontera límite para la realización de sus actividades.

De ese modo, al tiempo que se mantienen los conceptos de frontera límite, también se propone desarrollar en la cuarta sección el de frontera permisiva, tomando en cuenta la capacidad polisémica de frontera, en su versión poliédrica, como recurso y limitación (Renoldi, 2013), los usos territoriales (Sack, 1986) que diversos agentes despliegan, así como la superposición de territorialidades (Benedetti y Salizzi, 2011) que a través de la interacción resulta, generando así una nueva noción conceptual para comprender algunos de los fenómenos que suceden en la frontera México-Guatemala.

\section{Procesos de interacción, tensión y conflicto}

Los municipios de Ciudad Hidalgo y Tecún Umán constituyen un área conurbada diferenciada solamente por el río Suchiate que sirve como la demarcación internacional. Según fuentes censales, se estima una población en ambas demarcaciones de alrededor de 62491 residentes, de los cuales, 35056 pertenecen al lado mexicano (INEGI, 2010) y 27435 al lado guatemalteco. A este último volumen habría de sumarle una cantidad significativa de entre 20000 y 25000 personas en calidad de población flotante, pues Tecún Umán constituye un importante lugar de escala de inmigrantes provenientes básicamente de toda la región centroamericana, pero también de América Latina y Asia, ${ }^{2}$ que ocupan a dicha localidad como ciudad dormitorio previo al cruce a México.

En todos los municipios de la franja del río Suchiate se puede apreciar el comercio informal ${ }^{3}$ transfronterizo, pero sin duda alguna la zona de

${ }^{2}$ www.miniayutla.com

${ }^{3}$ Entenderemos respecto del concepto de informalidad, la condición social en la que se desarrollan actividades económicas, que si bien no están reguladas mediante una 
mayor transfronteridad (Iglesias-Prieto, 2010), medida por la cantidad de mercancía y número de actores que en ella participan, es la conurbación de Ciudad Hidalgo-Tecún Umán. En esta zona se encuentran seis cruces informales por donde la mercancía transita entre México y Guatemala, siendo los puntos de trasiego "El Limón”, "Los Rojos", "El Palenque”, "El Cascajo", "El Coyote" y "Las Hamacas" (figura 1), mencionados en orden de importancia por la intensidad en el flujo de bienes y personas.

A los comerciantes transfronterizos guatemaltecos (en adelante comerciantes transfronterizos $)^{4}$ se les observa a diario, desde la madrugada hasta alrededor de las 17:00 horas en la zona fronteriza en cuestión. Debido a no aceptar quetzales (moneda guatemalteca) en los locales de comercio ubicados en Ciudad Hidalgo, dicho actores acuden a los cambistas guatemaltecos, ${ }^{5}$ quienes en general, se enteran del precio del quetzal al momento de comprarlo en bancos guatemaltecos o mediante anuncios exhibidos exprofeso. Como resultado de la paridad del peso mexicano y el quetzal respecto del valor del dólar estadunidense, la moneda guatemalteca desde la década de los años noventa del siglo pasado ha venido comportándose a un nivel superior al del peso mexicano. Así, en 2012 se cambiaban 100 pesos mexicanos por 60 quetzales, siendo sin duda una de las razones principales por las que los guatemaltecos compran en México. Una vez hecho el cambio de moneda en Guatemala, los comerciantes transfronterizos se dirigen directamente al río Suchiate para cruzar a México, encontrándose en las márgenes del río con los camareros. ${ }^{6}$ En caso de que los comerciantes transfronterizos no hayan atravesado el río con el camarero de su confianza, al llegar al

intervención estatal, sí lo están por mecanismos basados en la confianza mutua, solidaridad o amenaza de exclusión social si se transgrede las normas laborales socialmente establecidas (Portes y Haller, 2004).

${ }^{4}$ Los comerciantes transfronterizos guatemaltecos son las personas que compran en México productos básicos industrializados para después venderlos en una determinada área de influencia al interior de Guatemala.

${ }^{5}$ Los cambistas son las personas que tienen por oficio el cambio de moneda, pueden ser de origen mexicano o guatemalteco. En este caso hablamos de cambistas guatemaltecos que se encuentran en la localidad guatemalteca de Tecún Umán.

${ }^{6}$ Los actores denominados camareros son los que prestan el servicio de traslado de bienes y personas a través del río Suchiate, sin registrar oficialmente sus movimientos. Utilizan dos cámaras de llantas de tractor — de ahí el nombre de "camareros"- sobre las cuales habilitan una tarima de madera formando así una especie de balsa (figuras 2 y 3 ). 
lado mexicano buscan o preguntan por él; éste, al constatar la presencia de su cliente, sabe que más tarde recibirá en diferentes tiempos mercancía comprada en México que ha de resguardar para su posterior tránsito hacia Guatemala. Esto último es un indicador de la existencia de las primeras interacciones entre comerciantes guatemaltecos y facilitadores de cruce de mercancía a partir de vínculos estables basados en la confianza, lo cual nos remite a la condición social de la informalidad (Portes y Haller, 2004).

Los comerciantes transfronterizos, situados del lado mexicano del río, se dirigen hacia la zona donde se ubican sus principales proveedores, los minoristas y mayoristas ${ }^{7}$ con quienes ocurre otra interacción más. Debido a que los comerciantes transfronterizos no compran en un solo local sino que van comparando precios y/o buscando lo que no encuentran en determinado lugar, después de haberles comprado a los tienderos, estos últimos envían la mercancía — mediante tricicleros - ${ }^{8}$ hacia la zona de los camareros, es decir, al río, al lugar de los distintos cruces en donde será resguardada y posteriormente transportada (figura 1).

Al llegar a la margen del río Suchiate, los tricicleros anuncian el nombre de quien compró la mercancía e inmediatamente ésta es recibida y resguardada por el camarero de confianza. Mientras tanto, el comerciante transfronterizo sigue en sus actividades de compra. Nuevamente encontramos un actor más, en este caso viene siendo el triciclero, personaje que interactúa entre el tiendero y el camarero.

Una vez finalizadas las compras, los comerciantes transfronterizos regresan a la margen mexicana del río Suchiate para esperar la última dotación que hayan adquirido mientras el camarero avanza en la colocación de los productos sobre la tarima de la cámara. Después, el comerciante, sentado sobre sus cajas de mercancía, es transportado a la margen guatemalteca de dicho afluente en donde el camarero descarga las compras,

\footnotetext{
${ }^{7}$ Los minoristas y mayoristas mexicanos son los propietarios de tiendas en la localidad de Ciudad Hidalgo.

${ }^{8}$ Los tricicleros, en este caso, son empleados de mayoristas y minoristas, y su oficio consiste en cargar y trasladar mercancía mediante su principal herramienta de trabajo de la cual reciben su nombre: el triciclo. Cabe señalar que el triciclo es un medio de transporte muy común entre los habitantes de la zona fronteriza, por lo que hay varios sindicatos de tricicleros en la región a los cuales no están adscritos los primeros, quienes no cuentan con ninguna asociación que los ampare laboral y jurídicamente.
} 
terminando así su labor. Inmediatamente los comerciantes transfronterizos y sus productos son transportados por los tricicleros guatemaltecos ${ }^{9}$ hacia la central de autobuses de Tecún Umán, y de ahí a las distintas localidades de Guatemala. Los tricicleros guatemaltecos asumen la figura de otro personaje más en esta interacción.

Figura 1. Dinámica socioeconómica transfronteriza en la zona Tecún Umán-Ciudad Hidalgo

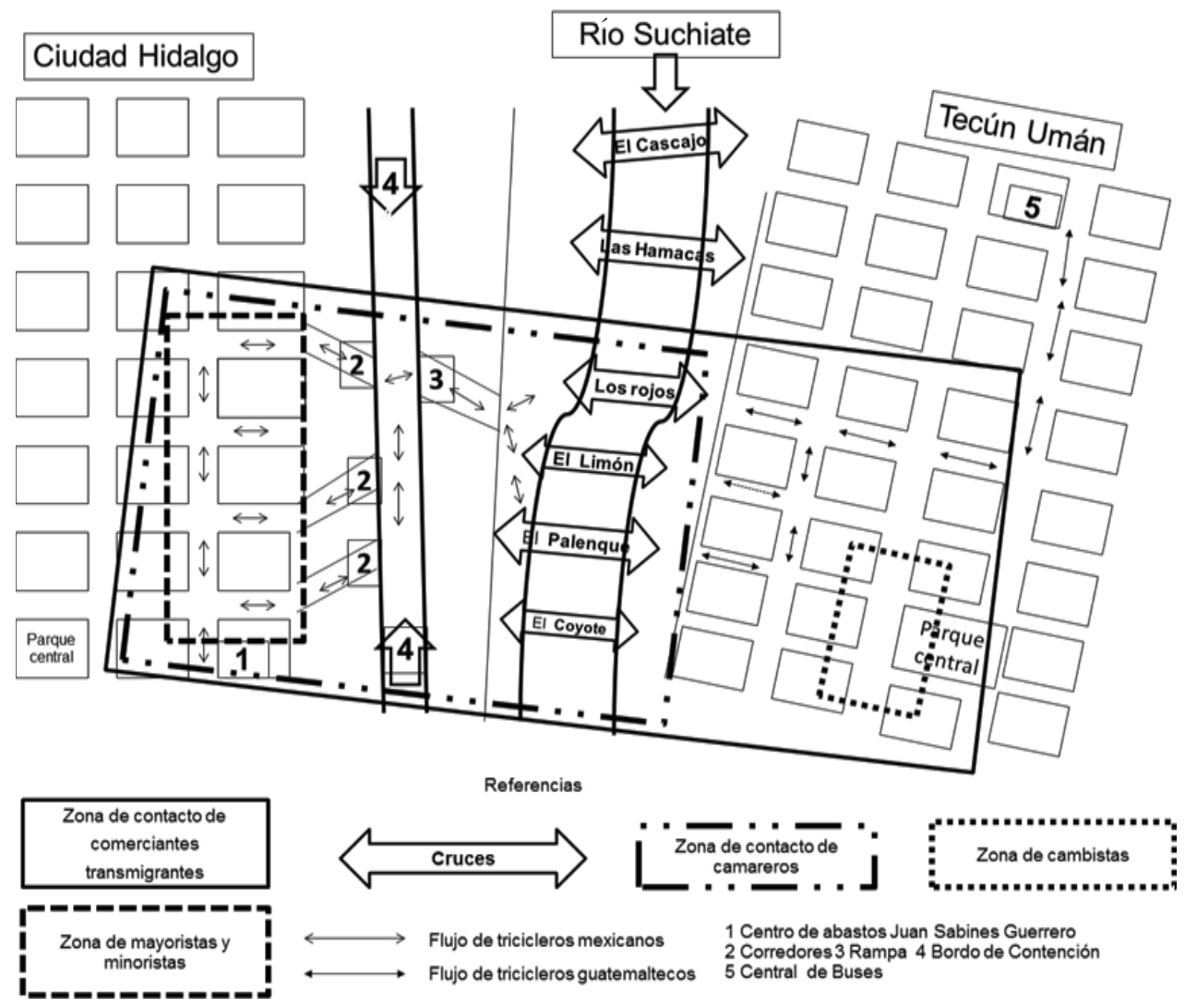

Fuente: Elaboración propia con base en observaciones de campo. Abril de 2012.

${ }^{9}$ Los tricicleros guatemaltecos son trabajadores pertenecientes a sindicatos de ese gremio. 
Carlos Ernesto Ruiz Juárez y Germán Martínez Velasco / Comercio informal transfronterizo México-Guatemala

En algunos casos llegan comerciantes transfronterizos con vehículos propios o contratan automotores de carga como pick ups y camionetas de redilas de tres a seis toneladas que estacionan de lado de Guatemala.

En el cruce "Los Rojos", de lado guatemalteco, hay un grupo de 20 personas que prestan el servicio de traslado de mercancía denominados en el argot de la zona pickuperos, adjetivo derivado del tipo de camioneta. De lo anterior, se puede deducir dos figuras sociales más del lado guatemalteco intervinientes en el comercio transfronterizo.

\section{Camareros}

Los camareros son quizá el eslabón más importante en la operación del comercio informal transfronterizo de la zona conurbada en cuestión. Por la comunicación que entablan con los comerciantes transfronterizos, el teléfono celular se ha convertido en una herramienta más de trabajo pues a través de dicho artefacto ocasionalmente los comerciantes solicitan a camareros que les compren y manden mercadería, previo giro del dinero en efectivo. Aunque el envío de mercancía es ocasional, la comunicación por celular es constante para conocer de ofertas o existencias de productos o cualquier otro imprevisto en la frontera. Por tal motivo, la comunicación por esta vía instala una interacción virtual entre oferta y demanda de productos, y de esa manera, le imprime un sello más dinámico a las transacciones, debido al conocimiento previo que otorga el uso telefónico como articulador indirecto entre tienderos mexicanos y comerciantes transfronterizos. Es entre ellos (camareros y comerciantes transfronterizos) donde encontramos la red social más fuerte, no obstante que las relaciones sean sólo de negocio ya que si se llegase a extraviar o mojarse la mercancía al grado de ser irrecuperable, los camareros estarían obligados a pagarla. Éste podría ser un punto de tensión entre ambos actores pese a las interacciones de antaño que pudieran tener; la interacción, si bien se basa en un nivel de confianza, básicamente ocurre mediante la instrumentalización recíproca entre sus personajes.

Un punto todavía más agudo de tensión y conflicto consiste en la separación del camarero de su puesto e instrumentos de trabajo. La mayoría de los que hoy se emplean como camareros tienen que pagar 50 quetzales 
diariamente a los propietarios de los puestos de dicho oficio. El pago solamente se omitiría por tres razones principales: $a$ ) ser fundador del cruce donde se trabaja; $b$ ) ser heredero de algún fundador; o $c$ ) haber comprado los derechos de la plaza a un fundador. Cabe señalar que entre los dueños de los puestos encontramos a quienes cuentan con más de uno, al grado de existir un oligopolio entre las personas propietarias de las plazas de camareros y de las cámaras también.

Otro tributo erogado por los camareros de los distintos cruces, sean fundadores o no, se refiere a la renta de cámara y vara (instrumento que utilizan para impulsarse sobre el río), siendo respectivamente de 40 y 5 quetzales diarios. Los propietarios de estos medios de trabajo son personas dedicadas a la compra, renta y mantenimiento de los mismos, mientras que los camareros son simplemente arrendatarios de dichos medios cuya renta la deducen de sus ingresos diarios. Es decir, camareros y propietarios de cámaras son dos subgrupos de actores independientes que se interrelacionan a partir del alquiler de las mismas.

Las representaciones sociales que inspiran los camareros son otra fuente de tensión, pues éstos asumen que han sido catalogados por parte de las autoridades mexicanas y guatemaltecas como delincuentes o, al menos, como personas de poco fiar debido a la sospecha que originan por el trasiego informal de personas y mercancías de uno a otro lado de la frontera. Una de las peticiones ante los gobiernos de ambos países consiste en "ser tratados con dignidad", ya que aclaran que los suyo "es trabajar sin importar lo que pudieran contener las cajas o cualquier otro empaque cuya propiedad es de los comerciantes" y no suya. Esto contrasta con la confianza entre camareros y comerciantes transfronterizos, pues solamente basada en ella, es posible desarrollar las actividades de información, compra de mercancía, su resguardo y su traslado.

Cada cruce cuenta con organización y reglamento propios que hacen posible los procesos de interacción. La organización laboral interna del cruce "Los Rojos" y "El Palenque" es similar debido a que ambos fueron fundados aproximadamente hace 40 años. Estos dos cruces a su vez están subdivididos en dos grupos de trabajo denominados "turno mexicano" y "turno guatemalteco", los cuales se dividen alternadamente los días de cada semana. Ambos turnos están representados por su respectiva asamblea, instancia de resolución de conflictos internos. Se reúnen cada mes 
para tratar asuntos originados durante las jornadas laborales, organizar la limpieza del área de trabajo, otorgar una cooperación monetaria para renta del espacio donde se agrupan y para integrar fondos de una caja de ahorro que ellos mismos administran y auxiliarse con préstamos en casos de accidentes laborales. Estas actividades sin duda son una muestra más de sus iniciativas de agencia, pues a pesar del carácter informal de las actividades, coadyuvan en la reproducción social de la organización, medio por el cual les permite posicionarse como grupo organizado no solamente ante el aparato público sino frente al resto de los demás actores, principalmente ante otros grupos de otros cruces.

Para llevar un control y evitar conflictos durante la jornada, los integrantes de cada turno deben anotarse en forma de lista cada vez que llegan a sus respectivas bases, es decir, al término de cada traslado. De este modo, llevan un orden sucesivo con la finalidad de que todos los que componen el grupo tengan igual oportunidad de realizar el mismo número de traslados. Las bases son el sitio donde los camareros aguardan a sus clientes y están ubicadas en ambos lados del río Suchiate. En el cruce "El Palenque" hay mayor disciplina en el control de la lista pues cada miembro debe encargarse de la misma durante una hora, anotando la cantidad de personas y mercadería que cada camarero transporta en un viaje. Lo anterior debido a que cada uno de ellos tiene derecho a ganar hasta 50 quetzales por traslado, evitando así aventajar a sus homólogos. De ese modo hay una mayor equidad en la distribución de clientes, por tanto, de los ingresos.

En contraste a los dos cruces anteriormente descritos, en el cruce "El Limón” los integrantes de la directiva tienen un único mando debido a que son los propietarios de las plazas de camareros. Dentro de este grupo, sin duda alguna la que ostenta más poder es una mujer líder propietaria de cuando menos 15 cámaras adscritas a distintos cruces, además de ser propietaria de sus respectivas plazas. En este cruce no hay los turnos mexicano y guatemalteco, como en los de "Los Rojos" y "El Palenque", sino un solo grupo de 45 camareros de ambas nacionalidades que tienen la posibilidad de trabajar toda la semana. De las 31 personas encuestadas, cinco (16\%) trabajan cinco días, 14 (45\%) laboran seis y 12 (38\%) de lunes a domingo.

Cabe señalar que una mayoría significativa de camareros es de origen guatemalteco residiendo en distintas localidades de ese país, pues $91.0 \%$ 
así se declaró, mientras que el restante $9.0 \%$ se declaró mexicano. Del subgrupo de camareros guatemaltecos, 27 (30\%) se distribuyen entre las localidades de Catarina, Coatepeque, El Triunfo, Malacatán, Mazatenango, Pajapita, El Tumbador y Reforma; mientras que 54 (61\%) son oriundos de la parte conurbada de Tecún Umán. Los camareros mexicanos en su mayoría son originarios de la otra parte conurbada de Ciudad Hidalgo.

\section{Minoristas, mayoristas y gobierno mexicano}

Los comerciantes transfronterizos tienen a sus principales proveedores en los minoristas y mayoristas mexicanos cuyos negocios existen por la demanda guatemalteca. Éstos son propietarios de tiendas familiares en las que participan los cónyuges, en algunos casos los hijos. Un punto a destacar de minoristas y mayoristas (al igual que con camareros), es el uso del celular para comunicarse constantemente con los comerciantes transfronterizos: 13 de los 16 minoristas que se encuestaron cuentan con teléfono móvil de la compañía Tigo y uno de Claro, cuyas coberturas principales se encuentran en Guatemala. Afortunadamente para ellos, la cobertura de dichas empresas abarca más allá de la línea fronteriza, ampliándose hacia varios puntos de Ciudad Hidalgo. Los restantes dos minoristas utilizan celular de la compañía Telcel que opera en territorio mexicano. El uso de la telefonía celular nuevamente sobresale como una instancia, a manera de nodo, de una red entre tienderos mexicanos y comerciantes transfronterizos haciendo más efectivo el viaje por parte de los últimos al saber previamente la existencia y costo de determinadas mercancías.

Cada negocio de mayoristas y minoristas se rige individualmente por decisiones de sus propietarios; a excepción de cuando algo afecta a todos, por lo cual, ambos grupos tienen un comité de representantes. Sin embargo, entre los mayoristas, debido a su mayor poder económico, están contemplando conformarse en grupo organizado con representación jurídica, sobre todo por situaciones como la que se describe a continuación.

Cuando ocurrió el histórico huracán Stan en 2005, mayoristas y minoristas estaban ubicados a unos metros de la margen mexicana del río Suchiate; a distancia muy cercana de los pasos de los distintos cruces. Los inmuebles, las bodegas y los productos resultaron afectados cerrando los 
establecimientos temporalmente, sin embargo, cuando las aguas regresaron a su cauce, estos actores volvieron a situarse en dicho lugar. Seis años después, en el año 2011, minoristas y mayoristas fueron reubicados por el gobierno estatal en el centro de abastos Juan Sabines Guerrero, construido especialmente para ellos, teniendo como justificación lo ocurrido con el mencionado fenómeno meteorológico. Además, en conjunto con la Comisión Nacional del Agua (Conagua), inició la construcción de un bordo de contención para "salvaguardar" a los habitantes de Ciudad Hidalgo ante la amenaza de otro huracán.

El bordo construido afectó severamente el traslado de mercancía de las tiendas mexicanas a la margen del río; entonces el gobierno de Chiapas prometió a los locatarios mexicanos construir una rampa a la altura del cruce "El Coyote" (figura 1) para facilitar el paso de los productos. No obstante, al término del sexenio de Juan Sabines Guerrero (2012) todavía seguía sin cumplirse. En 2012, la relación entre mayoristas y minoristas, y resto de actores transfronterizos con las autoridades gubernamentales mexicanas eran malas debido al incumplimiento en la construcción de dicha rampa. Entonces, muchos de los locatarios evadieron ocupar los locales del centro de abastos referido; en cambio, unilateralmente, se instalaron en calles y avenidas más accesibles a la zona de camareros hasta donde los tricicleros pudieran llevar la mercancía. Esto provocó división entre los inconformes con los que sí habían aceptado la reubicación.

Durante enero de 2013, los de mayor inconformidad llegaron hasta la rivera del río con vehículos habilitados a manera de locales improvisados para vender sus productos. Ante tal situación, ahora solamente les queda la opción de rentar casas habilitadas como bodegas ubicadas en calles y avenidas contiguas al lugar de los camareros.

Tal fue la magnitud de la problemática ocasionada por la construcción del bordo, según medios locales, que hasta empresarios de otros estados de la República mexicana que introducen productos a la zona fronteriza, resintieron la disminución en sus ventas, uniéndose a las protestas de los actores fronterizos y amenazando con desabastecer de productos básicos a los comerciantes locales. Fue el caso de José Luis Fernández, de la empresa Productora Nacional de Huevo "CRío", de Mérida Yucatán, cuyas ventas cayeron en $60 \%$ durante dos meses que llevaba el conflicto por la construcción del bordo referido (Scott, 2012). 
Finalmente, después de varias protestas y mesas de negociación entre gobierno mexicano y actores fronterizos (mayoristas, minoristas, tricicleros, camareros, etc.), durante el primer semestre del año 2013, el Estado convino construir, por un lado, una rampa a la altura del cruce "Los Rojos", y del otro lado corredores, superando así la barrera física impuesta por el bordo (figura 1).

Sin embargo, la tensión entre minoristas y mayoristas seguía latente, pues para los que decidieron quedarse en el centro de abastos sus triciclos hacen un mayor recorrido incrementando gastos de mantenimiento, además del aumento de salario para sus tricicleros.

De lo antes expuesto, resaltan tensiones y conflictos de distinta naturaleza y escalas. El primero ocurre con la intervención del Estado al momento de construir el bordo, situación que todavía permanece latente. El segundo se refiere al divisionismo causado a partir del mercado hecho especialmente para minoristas y mayoristas, pues todos, decidiendo desde sus propios intereses, unos aceptando su reubicación, otros optando por reinstalarse por cuenta propia en terrenos cercanos, definen la forma más conveniente en la comercialización de sus productos.

\section{Dimensión económica del comercio informal transfronterizo}

Para describir algunos aspectos importantes de la dimensión económica de la conurbación Tecún Umán-Ciudad Hidalgo, basta tomar en cuenta aspectos económicos-laborales de los camareros, la derrama económica de los comerciantes transfronterizos guatemaltecos de lado mexicano y el ingreso monetario por concepto de ventas de minoristas y mayoristas.

Como apuntamos anteriormente, la mayoría de los camareros necesitan pagar renta por sus puestos de trabajo. De los 89 encuestados, 65 (73\%) pagan 50 quetzales por jornada, mientras que 24 (27\%) están libres del pago. En cuanto a ingresos monetarios netos a la semana, en promedio cada camarero gana 386 quetzales, equivalente a 640 pesos mexicanos, según el tipo de cambio durante el trabajo de campo.

Los camareros tienen a sus principales clientes en los comerciantes transfronterizos cuya actividad es fundamental para la vida económica de la zona de estudio. De los 89 camareros encuestados, 70 (79\%) cuentan 
con clientes fijos, los restantes 19 (21\%) trabajan con clientes sin preferencia por alguno de ellos. Los 70 señalados tienen un total de 325 comerciantes transfronterizos fijos que frecuentemente visitan la frontera. De los volúmenes de mercadería que transportan sus clientes, los camareros solamente pudieron ofrecer información de 192 (59\%) de los 325 contabilizados. Estos 192 mercaderes transportan en conjunto hacia Guatemala 224 camarazos $^{10}$ de productos a la semana.

En el argot de la zona existe el medio camarazo, $3 / 4$ de camarazo, un camarazo, camarazo de dos a tres pisos, camarazo de tres a cuatro pisos, etc., por cuyo traslado, dependiendo del tipo y volumen de mercadería, los camareros en verano cobran desde 30 hasta 250 quetzales; en invierno cobran un poco más debido a las dificultades que presenta pasar en el raudal. Los más frecuentes son los camarazos de dos a tres pisos. Por ejemplo, en el de la figura 2 se observan 50 cajas de huevo cuyo costo unitario durante la estancia en la zona era de 380 pesos mexicanos, lo que equivale un costo total del producto de 19000 pesos mexicanos. Independientemente del tipo de producto, en promedio, el valor de la mercancía que un camarero

Figura 2

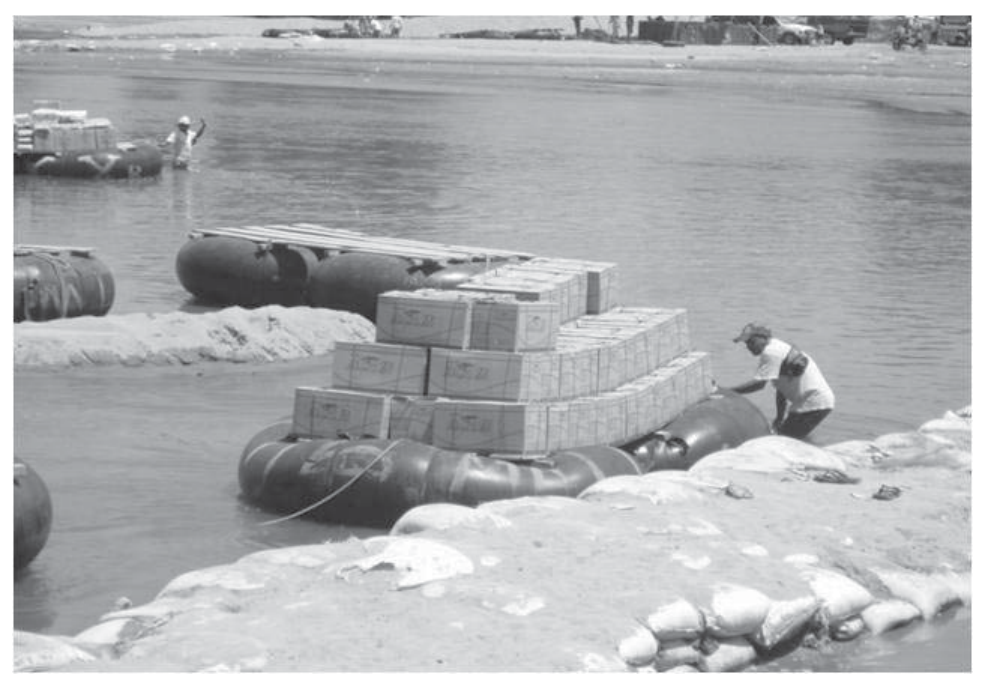

${ }^{10}$ Un camarazo en la jerga laboral es la medida que los camareros utilizan para cuantificar la cantidad de mercancía transportada (figuras 2 y 3 ). 
Figura 3

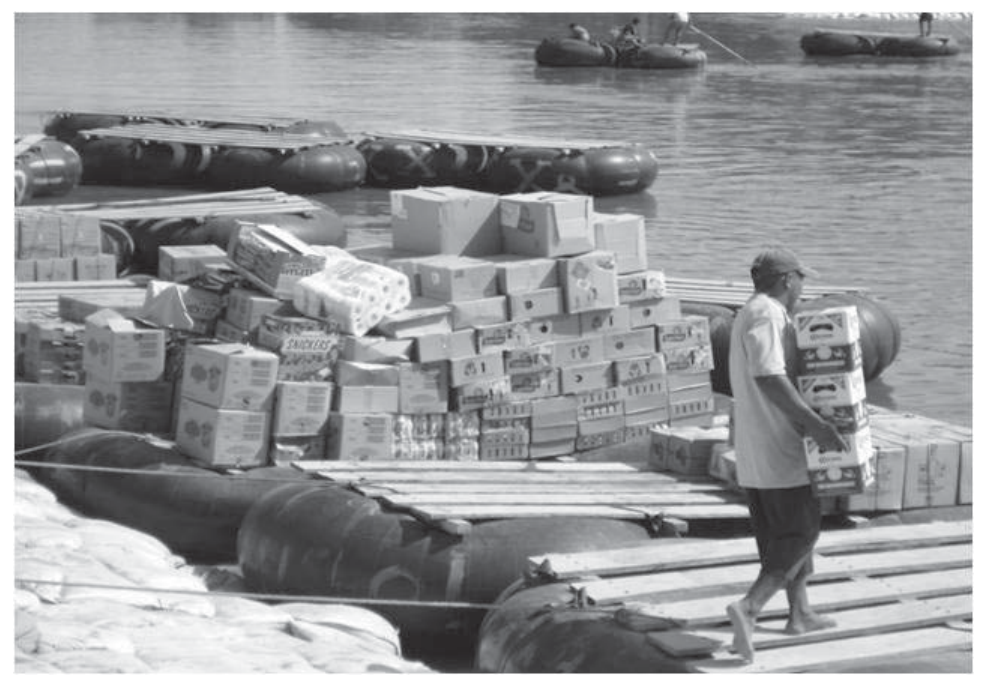

traslada de un lugar a otro oscila entre los 15000 y 35000 pesos mexicanos.

Los comerciantes transfronterizos trasladan hacia Guatemala productos industrializados en sus distintas presentaciones y marcas. Alimentos de primera necesidad como huevo, maíz, frijol en grano y enlatado, sal y arroz. Comestibles diversos entre los que destacan la soya, pastas para cocinar e instantáneas, agua embotellada de 1/4 de litro, leche líquida y en polvo, yogur, harina para tortillas y pan, aceite, galletas, café soluble, mayonesa, chiles enlatados, sardinas enlatadas, salchichas, refrescos embotellados, cervezas, entre otros. También destacan artículos de limpieza personal y de hogar como papel higiénico, pasta dental, jabón de tocador y para lavado de ropa, aromatizantes líquidos y cloro. Entre otros artículos están zapatos de compra instantánea y de catálogo, utensilios de plástico donde se encuentran los denominados topers, cable para televisión e instalaciones eléctricas, veladoras, tubos para drenaje, sanitarios, e insumos varios. Cabe hacer mención que también se trasladan frutas de temporada como mango, papaya, naranja, melón y verduras como cebolla y jitomate principalmente. 
Si se toma el monto mínimo de los camarazos (15 000 pesos mexicanos) y se multiplica por 224 traslados a la semana, se tiene una derrama económica de 3360000 pesos semanales, proveniente de los comerciantes transfronterizos; cantidad producida solamente por los 192 de los que se tiene registro, por lo que dicha cantidad es sólo una parte del consumo guatemalteco.

En promedio, los minoristas reciben por concepto de ventas 345916 pesos mexicanos al mes, oscilando los de menor y mayor cantidad entre los 11000 pesos y 1260000 pesos mexicanos, respectivamente. En relación con la cantidad de personal empleado, los 16 minoristas en promedio emplean a cinco trabajadores que se ocupan sea como cargadores o tricicleros; mientras que los de menor y mayor volumen de ventas cuentan con uno y 35 trabajadores, respectivamente. En total, los 16 minoristas emplean a 80 personas. Como no se cuenta con mayor información sobre los mayoristas que la proporcionada por su líder, sólo se puede señalar que las ventas de este grupo van desde los 100000 hasta los 200000 pesos mexicanos diarios por negocio. Según dicho personaje, en Ciudad Hidalgo las ventas ascienden a 2000000 de pesos diarios por el comercio informal transfronterizo.

En síntesis, la conurbación Ciudad Hidalgo-Tecún Umán constituye un espacio integrado de intercambios económicos y sociales, basados fundamentalmente en el eje conformado por el comercio transfronterizo informal. De esta actividad se desprende una serie de actores vinculados con distintos grados de interacción con cuyas prácticas, conflictos y tensiones producen un ambiente de frontera. Hay interacciones de primer orden y otras de segundo. En primer término, se encuentran aquellas cuyos actores se identifican con códigos compartidos, tales como: $a$ ) las de los comerciantes transfronterizos guatemaltecos y los camareros; b) las de los comerciantes transfronterizos y los minoristas y mayoristas mexicanos (tienderos); c) las de los tienderos mexicanos con las distintas instancias gubernamentales asociadas a la regulación territorial de los establecimientos. Las de segundo orden consisten en: a) las de los tricicleros guatemaltecos y mexicanos con sus respectivos clientes: comerciantes transfronterizos; $b$ ) las que ocurren al interior de los distintos grupos de camareros agrupados por cruce; y $c$ ) las de un grupo con los restantes grupos de camareros. En cada una de las interacciones están presentes 
conflictos que generan tensiones, unas de grado menor (comerciantes transfronterizos y camareros) y otras de mayor trascendencia, sean permanentes o de duración indefinida. Las permanentes aluden a la desigualdad en el acceso de los recursos como las plazas (cobro de derecho de piso) y renta de medios de trabajo (cámaras y varas). Las de duración indefinida se refieren a la inesperada intervención del Estado mexicano mediante la construcción del bordo que no solamente puso en tensión a los tienderos mexicanos con las instancias gubernamentales sino entre éstas con aquellos otros personajes intervinientes en el comercio transfronterizo, incluyendo la tensión surgida al interior del grupo de minoristas y mayoristas.

\section{Ensayo de interpretación final}

La zona conurbada de Ciudad Hidalgo-Tecún Umán en tanto escenario no solamente de paso de indocumentados sino de fuerte actividad social y comercial revelado por sus interacciones y el monto de sus transacciones económicas, adquiere en el contexto de la frontera México-Guatemala un alto nivel de transfronteridad (Iglesias-Prieto, 2010), pues a lo largo de ésta, dicha zona sobresale como punto de mayor intensificación de contacto transfronterizo. Esto es producto de condiciones geográficas adecuadas, demográficas, y de una mayor interconexión terrestre y satelital que propicia el establecimiento de una red de comunicación. También de una continuidad cultural y de relación histórica que hay entre los habitantes de los municipios fronterizos de México y Guatemala. Estas condiciones habrían de configurar un área dinámica de tipo comercial, alimentada por una constante oferta y demanda de productos básicos industrializados de cuyo centro habría de gravitar toda una serie de interacciones, involucrando una diversidad de actores física y electrónicamente a través de celulares.

Las prácticas sociales de los distintos actores se llevan a cabo previa valoración (Ruiz, 1992), pues, por una parte, quienes detonan el fenómeno (comerciantes transfronterizos y tienderos mexicanos) advierten que la adyacencia de diferencias estructurales (Alegría, 1989, 1990), les permitirá hacer un uso instrumental de la frontera. Es así que los comerciantes 
transfronterizos guatemaltecos mediante su agencia permean la frontera límite (Turner, 1987) previa valoración de las utilidades a obtener, mientras que sus contrapartes mexicanas invierten aun cuando el tamaño del mercado conurbado sea pequeño, sabiendo que mediante los intermediarios (comerciantes transfronterizos) sus productos alcanzarán llegar allende la frontera. El otro personaje de relevancia consiste en los camareros quienes previa valoración de su importancia en el trasiego de personas y mercancías, independientemente de su origen nacional, asumen conductas territoriales de uno y otro lado del río sin importar la frontera límite. En alusión a lo anterior, es menester incorporar aquí la comprensión de territorialidad, y su valor argumentativo cuando más adelante se desarrolle la noción de frontera permisiva. "La territorialidad se define como el intento por parte de un individuo o grupo de afectar, influir, o controlar a las personas, fenómenos y relaciones, delimitando y reafirmando el control sobre un área geográfica” (Sack, 1986, p. 26).

Entendidas las fronteras como recurso y limitación (Renoldi, 2013), para el caso que atañe, esto se convierte en oportunidad (recurso) de las diferencias estructurales adyacentes, al capital humano con que se cuenta (camareros), sus medios de transporte y comunicación de un país a otro, y la diferencia en el tipo de cambio de moneda. Sin embargo, aunque haya un uso territorial de determinados espacios, la presencia del Estado se convierte en una limitación. Es una realidad hecha presente cuando ejerciendo su poder institucional interviene aplicando el punto de vista de su política pública, mediante la reorganización territorial del comercio establecido, la construcción de bordos, la edificación de una central de abastos y la presión correspondiente para reubicar a tienderos, afectando así, la logística comercial en su conjunto. Por lo anterior, estamos de acuerdo con Grimson (2001) en que debe tomarse en cuenta el papel del Estado en la redefinición de las zonas de frontera, pues las actividades de la población fronteriza pueden verse directamente afectadas por decisiones gubernamentales.

La tesis presentada aquí en relación con el planteamiento de frontera permisiva encuentra su fundamentación en la noción de superposición de territorialidades proveniente de Benedetti y Salizzi (2011), así como en la definición de territorialidad previamente enunciada. En el comercio transfronterizo informal hay al menos tres actores claves con sus respectivas 
agencias definiendo sus ámbitos de influencia y control en sus relaciones, delimitando y reafirmando un área geográfica. Estos actores son: el Estado, los camareros y los tienderos mexicanos.

El Estado en su pretensión soberana establece sus límites territoriales en su carácter de frontera límite, y con ello, despliega disposiciones unilaterales, sin embargo, aun con dispositivos institucionales y de control, deja margen de tolerancia y es permeado territorialmente tanto por el ingreso de camareros de origen guatemalteco a territorio nacional, como por la agencia de tienderos mexicanos en la disposición de espacios. Los camareros, mayoritariamente de origen guatemalteco, al ocupar las márgenes nacionales del río Suchiate e introducirse al municipio mexicano, hacen usos territoriales del espacio fronterizo, además de acotar de forma exclusiva esta actividad para aquellos que formalmente han sido reconocidos por sus propias reglas dirigentes. Es decir, la agencia territorial de los camareros incluso no solamente ocurre frente al Estado mexicano sino también entre quienes conforman su gremio al establecer con extrema precisión sus distintos corredores de cruce transfronterizo, y el resguardo de las plazas para desarrollar el trasiego de bienes y personas, sean éstas compradas, rentadas o heredadas, funcionando a manera de filtro para sus eventuales aspirantes. Por último, se encuentran los tienderos mexicanos que con su agencia evaden las disposiciones gubernamentales $\mathrm{y}$, actuando territorialmente, establecen una lucha por el espacio; antes en territorios acordes a las circunstancias de cercanía geográfica con los camareros, y ahora, evadiendo una condición de obligatoriedad, disuaden al Estado al negarse a ocupar un territorio estatal representado en la central de abastos, y en cambio, ocupan territorios nuevos con miras a normalizar las rutinas transfronterizas.

En el espacio mexicano de Ciudad Hidalgo, territorio contenido en los límites del Estado-nación, hay una superposición de territorialidades cuyo centro de explicación se encuentra en la simultaneidad de agencias que los actores despliegan en relación con el comercio transfronterizo informal. La superposición territorial, como se ha expuesto, reside en la existencia paralela de actuaciones territoriales, la primera anidada en la legitimidad formal adjudicada en el Estado-nación desplegando acciones acordes a sus alcances en términos de frontera límite. Las dos restantes, en los despliegues de actuación que los actores hacen en aras de intereses 
propios, unos de menor pretensión (los camareros), otros de mediana (minoristas) y otros hasta en situación de acumulación de capital (tienderos mayoristas).

La frontera permisiva no solamente se acuña con los modos de intervención de los actores antes mencionados, sino también, como ya se dijo, con los de los comerciantes transfronterizos guatemaltecos que usan los cruces informales para desarrollar su actividad. Por su parte, los comerciantes transfronterizos guatemaltecos, sin hacer usos territoriales del espacio, acceden y abandonan el territorio mexicano sin registro alguno, transitando cotidianamente en un escenario de transacciones e interacciones con los distintos personajes en cuestión. La actuación de los tres últimos actores (camareros, tienderos y comerciantes transfronterizos) se basa en la ausencia de una problematización de su condición fronteriza, pues encuentran su razón de ser en una contigüidad limítrofe, basada en usos y costumbres nacidos del devenir común. Se trata de sociedades establecidas en una geografía que históricamente los unifica, de limitantes y oportunidades, re-produciendo en el día a día una cercanía no solamente sociocultural, sino también emocional. La permisividad del Estado mexicano también se refiere a los márgenes disponibles de actuación para los actores locales nacionales, es decir, la de los tienderos mexicanos. Siendo interacciones conscientes, su sentido es el interés de dinamizar una economía regional, incentivando no solamente la generación de ganancias de los tienderos, sino de ciertos eslabones comerciales de la economía mexicana en general.

El conjunto de apuntes anteriores dibuja a este espacio de la frontera México-Guatemala como lugar donde convergen procesos de la historia inmediata, como ha sido el afianzamiento de este mercado integrado transfronterizo, definiéndose como una dimensión social (Grimson, 2000a, 2000b y 2001; Iglesias-Prieto, 2010; Odgers, 2006; Ojeda, 2009; Ruiz, 1992), que es animada por la forma en que los distintos personajes "hacen la frontera" (Andrade, 2010, p. 180). Los actores fronterizos "hacen la frontera" no solamente con las rutinas laborales, sino, sobre todo, a través de su agencia, induciendo procesos de cambios según sean sus intereses. 


\section{Bibliografía}

Albuquerque, J. L. (2010). As fronteiras ibero-americanas na obra de Sérgio Buarque de Holanda. Análise Social, XLV(195), 329-351.

Alegría, T. (1989). La ciudad y los procesos transfronterizos entre México y Estados Unidos. Frontera Norte, 1(2), 53-90.

Alegría, T. (1990). Ciudad y trasmigración en la frontera de México con Estados Unidos. Frontera Norte, 2(4), pp. 7-38.

Alegría, T. (2007). La visión de la metrópolis transfronteriza. Crítica y evidencias en el caso de Tijuana y San Diego. Observatorio experimental sobre las migraciones internacionales en las áreas urbanas de América Latina (pp. 27-50).

Andrade, M. (2010). Espacios fronterizos e identidad. Tensiones y estrategias político-culturales en la ciudad de Concordia. RUNA, 2(xxxI), 175-190.

Benedetti, A. y Salizzi, E. (2011). Llegar, pasar, regresar a la frontera. Aproximación al sistema de movilidad argentino-boliviano. Transporte y Territorio, (4), 148-179.

Bustamante, J. (1989). Frontera México-Estados Unidos: Reflexiones para un marco teórico". Frontera Norte, 1(1), 7-24.

De Vos, J. (2002). La frontera sur y sus fronteras, una visión histórica. En E. Kauffer (Ed.). Identidades, migraciones y género en la frontera sur de México (pp. 1-270). San Cristóbal de Las Casas Chiapas, México: El Colegio de la Frontera Sur.

Dorfman, A. y Cardin, E. (2014). Estratégias espaciais do ativismo em condicao fronteirica no Cone Sul. Cuadernos de Geografía, Revista Colombiana de Geografía, 23(2), 31- 44.

Fábregas, A. (1996). El concepto de frontera en la frontera sur. Gobierno del Estado de Chiapas.

Grimson, A. (2000a). Pensar fronteras desde las fronteras. Nueva Sociedad, (170), $1-5$.

Grimson, A. (2000b). Cortar puentes, cortar pollos. Conflictos económicos y agencias políticas en Uruguayana (Brasil)-Libres (Argentina). Revista de Investigaciones Folclóricas, 15, 66-76.

Grimson, A. (2001). Fronteras, Estados e identificaciones en el Cono Sur 2. En D. Mato, (Comp.), Estudios latinoamericanos sobre cultura y transformaciones sociales en tiempos de globalización (pp. 89-102). Caracas y Buenos Aires: Unesco, Consejo Latinoamericano de Ciencias Sociales.

Iglesias-Prieto, N. (2010). Trascendiendo límites: La frontera México-Estados Unidos en el cine. Fiar. Forum for Inter-american Research, 3.2(2). Recuperado de <http://www.interamerica.de/category/volume-3-2/>

Kauffer, E. (2005). De la frontera política a las fronteras étnicas. Refugiados guatemaltecos en México. Frontera Norte, 17(34), 7-36. 
Carlos Ernesto Ruiz Juárez y Germán Martínez Velasco / Comercio informal transfronterizo México-Guatemala

Martínez, G. (2014). Inmigrantes laborales y flujo en tránsito en la frontera sur de México: Dos manifestaciones del proceso y una política migratoria. Revista Mexicana de Ciencias Políticas y Sociales, (220), 261-294.

Odgers, O. (2006). Cambio religioso en la frontera norte. Aportes al estudio de la migración y las relaciones transfronterizas como factores de cambio. Frontera Norte, 18(35), 111-134.

Ojeda, N. (2009). Reflexiones acerca de las familias transfronterizas y las familias transnacionales entre México y Estados Unidos. Frontera Norte, 21(42), 7-30.

Ordoñez, C. (2005). Regiones y tendencias de integración económica fronteriza entre Chiapas y Guatemala. En P. Bovin (Dir.). Las fronteras del istmo: Fronteras y sociedades entre el sur de México y América Central. Centro de Estudios Mexicanos y Centroamericanos, México. Recuperado de: <http://books.openedition. org/cemca/711>

Portes, A. y Haller, W. (2004). La economía informal. Serie Políticas Sociales 100. Santiago de Chile: Comisión Económica para América Latina y el Caribe.

Renoldi, B. (2013). Fronteras que caminan: Relaciones de movilidad en un límite trinacional. Transporte y Territorio, (9), 123-140.

Rodríguez, A. (2008). La Iniciativa Mérida en su contexto histórico. En Instituto para la Seguridad y la Democracia (Insyde) (Comp.), La Iniciativa Mérida: Seguridad, soberanía y migración en la relación México-Estados Unidos (pp. 1-14). México.

Ruiz, O. (1992). Visitando la patria: Los cruces transfronterizos de la población estadounidense de origen mexicano. Frontera Norte, 4(7), 103-130.

Sack, R. D. (1986). La territorialidad humana, su teoría y la historia. Nueva York: Cambridge University Press.

Scott, D. (10 de octubre de 2012). Colapsa economía fronteriza por el conflicto en Suchiate. El Orbe de Tapachula.

Sistema de Información sobre Comercio Exterior (2014). Tratados de libre comercio firmados por México y países centroamericanos, 2014. Organización de los Estados Americanos. Recuperado de: <http://www.sice.oas.org/TPD/ CACM_MEX/CACM_MEX_s.asp>

Villafuerte, D. (2008). Migración y desarrollo en el área del Plan Puebla-Panamá. En D. Villafuerte y M. García (Coords.), Migraciones en el sur de México y Centroamérica (pp. 1-391). México: Universidad de Ciencias y Artes de Chiapas, Miguel Ángel Porrúa. 